\title{
Antioxidant Activity, Skin Irritation Potential and Chemical Composition of Clove Leaf Oil from West Java Indonesia
}

\author{
D. Rahmi*, R. Yunilawati, I. Setiawati, Irwinanita, B. N. Jati, A. Riyanto, Yemirta and N. N. Aidha \\ Center of Chemical and Packaging, Ministry of Industry, Jl. Balai Kimia I Pekayon, Pasar Rebo, Jakarta 13710, Indonesia
}

\begin{abstract}
Essential oils with specific chemical compositions have the potential as a source of antioxidants in cosmetics, however, in general, essential oils are not safe because of the potential for skin irritation. This study aims is to perform fractionation to obtain clove oil with a chemical composition that is safe on the skin and does not reduce its antioxidant activity. Fractionation was performed at a temperature of $100-285^{\circ} \mathrm{C}$. Chemical composition was determined by Mass Chromatography Spectrometry (GC-MS), antioxidant activity by DPPH method, and irritation potential by in-vivo patch test. The results showed chemical components of clove oil were eugenol, copaene, beta caryophyllene, iso-eugenol, alpha caryophyllene, cadinene, caryophyllene oxide, caryophylla and beta caryophylla. Fractions with chemical compositions of eugenol and beta caryophyllene as the main components and copaene, iso-eugenol, alpha caryophyllene, cadinene as secondary components have very light erythema and no potential irritation to the skin. The fraction produced from the fractionation of crude clove oil at a temperature of $235-260^{\circ} \mathrm{C}$ has the highest antioxidant activity of $10.17 \mathrm{mg} / \mathrm{L}$.
\end{abstract}

\section{ARTICLE HISTORY}

Received: 4 June 2021

Revised: 25 October 2021

Accepted: 29 October 2021

\section{KEYWORDS}

Clove oil

Antioxidant activity

Potential skin irritation

\section{INTRODUCTION}

Essential oils are plant extracts consisting of complex organic substances with a distinctive aroma [1]. The composition of compounds and functional groups in essential oils determines the organoleptic properties and biological activities including antioxidant activity, antibacterial activity, and anti-inflammatory activity [2]. Essential oils have been used regularly in cosmetics because they have a pleasant aroma [3]. Over time essential oils are not only known as aromatherapy but also have other activities including antioxidant activity [4]. All essential oils have antioxidant activity with different oxidation-inhibiting abilities for each type. Essential oils that have phenolic elements such as those in leaves and twigs of Vireya Rhododendron from Indonesia have antioxidant capacity until $1793.62 \mu$ mol trolox/g dried powder [5]. Beside the elements contained, chemical composition of essential oil also determines its antioxidant activity [6].

Clove oil consists of the main components eugenol $(50-80 \%)$, carryophyllene $(4-20 \%)$, and more than 20 types of other components [7]. Clove oil is produced from the distillation of the leaves of cloves. The distillation conditon process determines the percentage of chemical composition. The main composition clove bud oil from West Java Indonesian obtained by PT. Indesso is eugenol 77.53\%, $\beta$-caryophyllene 5.90\% and eugenyl acetate $12.07 \%$ [8]. Eugenol is a phenolic which have high antioxidant activity that $\mathrm{IC}_{50}$ values below $50 \mu \mathrm{g} / \mathrm{mL}$ [2]. The antioxidant activity of clove oil is higher than the antioxidant activity of synthetic butylated hydroxytoluene (BHT) [6]. The inhibition of oxidation of clove oil was $94.18 \%$ higher than that of synthetic antioxidants BHT by $92.15 \%$ [9]. Meanwhile, in another study, it was found that the inhibition of BHT oxidation was greater than that of trolox which was indicated by the lower antiradical activity of BHT $16.14 \mu \mathrm{M}\left(\mathrm{IC}_{50}\right)$ compared to trolox $23.84 \mu \mathrm{M}\left(\mathrm{IC}_{50}\right)[10]$. According to the Boulebd, H., 2020 the antiradical potential BHT>BHA > Trolox >ascorbid acid. BHT, BHA, and ascorbic acid (vitamin C) is used in similar food applications, while Trolox (vitamin E derivatives) is medicinal and industrial applications [10]. The need for cosmetic antioxidants increases especially for the elder because our skin becomes old due to physiological changes [11]. Currently, the urge to use natural ingredients as a source of antioxidants such as plant extracts is increasing to meet the antioxidant needs of the cosmetic industry $[12,13]$.

Essential oils have a great opportunity as a source of antioxidants, however, the complex compounds and chemical components in essential oils have caused the potential sensitivity allergic reactions be present in cosmetics, topical pharmaceuticals and household products [14]. It is known that essential oils with alcohol, phenol, and aldehyde functional groups [13] have a very high potential for irritation. Phenol compounds such as eugenol have an allergic effect on the skin [3], therefore it is necessary to research the use of clove oil as a safe antioxidant in cosmetics. The aims of this study were to determine the antioxidant activity, the allergy potential and chemical composition of clove oil and its fractions. This paper is expected used as a reference in selecting the chemical composition of clove oil to be used as a source of cosmetic antioxidants. 


\section{EXPERIMENTAL METHOD}

The research was conducted at the research laboratory of the Center of Chemical and Packaging, Ministry of Industry, Jakarta, Indonesia.

\section{Materials and Instruments}

Crude clove leaf oil was obtained from PT Sinkona International Lestari which was placed on Tasikmalaya, West Java, latitude -7.319563 and longitude 108.202972. While DPPH (2,2-diphenyl-1-pikrilhidrazil), L(+)-Ascorbic Acid, and ethanol for Spectrophotometric Grade was obtained from Sigma-Aldrich.

Spinning Band Column Distillation 9600 Series with M690 fractionation tool program was used as fractionation equipment. Moreover, this study also used analytical balances and other glassware.

\section{Method and Procedure \\ Fractionation}

Fractionation was carried out to obtain clove oil fraction with several chemical compositions. In this study, the fractionation was carried out using a Spinning Band Equipment. The chiller temperature was set at $20{ }^{\circ} \mathrm{C}$. Samples of clove oil was placed on the flask of raw material and boiling chips were put into the flask. Furthermore, the heating mantle and flask containing the sample were mounted on the tool column. The vacuum pump was turned on and the fractionation temperature was set at $100-125^{\circ} \mathrm{C}, 125-236{ }^{\circ} \mathrm{C}, 236-260{ }^{\circ} \mathrm{C}, 260-285{ }^{\circ} \mathrm{C}$. The pressure was at $17.2 \mathrm{mmHg}$ and the process heat rate was $50 \%$. Fractionation was carried out until the final temperature was reached and the fraction product was accommodated in the product bottle.

\section{Chemical Composition Test}

Chemical composition was tested using Gas Chromatography Mass Spectrometry (GC-MS) with Agilent brand, type GC 6890/MS 5975 MSD, the column was HP5-MS capillary column (30 m x $0.25 \mathrm{~mm}$ x $0.25 \mathrm{~m}$ ). The operating conditions were carried out with the initial temperature: $60{ }^{\circ} \mathrm{C}$ for 5 minutes. Then it increased at a speed of $10{ }^{\circ} \mathrm{C} / \mathrm{min}$ to a temperature of $250^{\circ} \mathrm{C}$ and maintained it for 5 minutes. The split ratio was 1:20. Helium was used as a carrier gas at a constant pressure of 7.65 psi.

\section{Antioxidant Test}

The antioxidant testing method was taken from the method of Rafi et al, 2018 with modifications. First of all, $1 \%(\mathrm{w} / \mathrm{v})$ essential oils sample was dissolved in ethanol p.a. and then this solution was divided in half as a negative correction. Elsewhere, a $0.1 \mathrm{nM}$ DPPH solution in ethanol p.a. was prepared. After that, DPPH solution and the volatile oil sample solution were mixed in a ratio of $1: 1$. In another place, $15 \mathrm{mg} / \mathrm{L}$ ascorbic acid solution was prepared in ethanol p.a. And then, a series of ascorbic acid solutions were made with successive concentrations of $0,1.5,3,4.5,6,7.5 \mathrm{mg} / \mathrm{L}$. Then, the absorbance was measured at a wavelength of $517 \mathrm{~nm}$ using a UV-VIS Spectrophotometer. Antioxidant activity was determined by determining the concentration in $\mathrm{mg} / \mathrm{L}$.

\section{Skin Irritation Potential Test}

The test method is In-Vivo Semi Occlisive Single Patch Testing and clinical evaluation by Spincontrol Idea Indonesia. The test was conducted by involving 33 people as test subjects. Subjects were selected based on the criteria of healthy Asian men and women aged 18-65 years, having various skin types such as dry skin, oily skin and combination skin. First of all, each subject filled out a health and cosmetic use questionnaire. Subjects did not use cosmetics on the back for 12 hours before starting the test. Then, apply the sample to the subject's back. After 48 hours the back skin is cleaned. Subsequently, a clinical evaluation was carried out on the back skin that was attached to the sample. The assessment criteria are divided into 4 types; first, no effect if there is no change in skin color; second, mild irritation if the skin becomes pink; third, moderate irritation if the skin turns to be pinkish-red; and finally severe irritation if the skin becomes red.

\section{RESULT AND DISCUSSION Chemical Composition}

Clove oil has about thirty-two components [8]. Based on the GC-MS chromatogram (Table 1), it is known that West Java Indonesian clove oil consists of ten types of components detected with concentrations above $0.1 \%$. The crude oil in this study had a relative density of $1.02 \mathrm{~g} / \mathrm{mL}$, a refractive index of 1.553 , and an optical rotation of -0.37 and was fractionated at a temperature of $100{ }^{\circ} \mathrm{C}$ to $285^{\circ} \mathrm{C}$. Fractionation was divided into four process temperature ranges such as fraction- 1 at temperature of $100-125{ }^{\circ} \mathrm{C}$, fraction- 2 at a temperature of $125-235{ }^{\circ} \mathrm{C}$, fraction- 3 at a temperature of 235 $-260{ }^{\circ} \mathrm{C}$, and fraction-4 at a temperature of $260-285^{\circ} \mathrm{C}$ which were accommodated in pot-1, pot-2, pot-3 and pot-4, respectively. This temperature division was carried out to separate eugenol as the main component from other components. Fraction-1 which accommodated in pot-1 was a very light and volatile component that is lost during the process and could not be tested. Fraction-1 was thought to be terpene or alcohol compounds such as pinene, eucalyptol, chavicol, linalool, dodecane as also detected in Chinese clove oil [7]. In this study, 2.5 L of crude clove oil produced 0.1 
$\%(\mathrm{v} / \mathrm{v})$ fraction- $-2,92 \%(\mathrm{v} / \mathrm{v})$ fraction- $3,0.05 \%(\mathrm{v} / \mathrm{v})$ fraction- 4 and left it about $0.4 \%$ as a residue. Based on the volume of the resulting fraction, there is $7.45 \%$ of the product lost during the process. It might be a very light component that evaporates during processing or remains in the pot when measured.

The chemical composition of crude clove oil, fraction-2 product, fraction-3 product, fraction-4 product and residues are summarized in Table 2. In this study, the chemical components indicated by the library of GC-MS. The main components with a concentration of $20-90 \%$ in clove oil, fraction and residue are eugenol and beta caryophyllene, while the secondary components with a concentration of $1-20 \%$ and minor components range of $0-1 \%$ are found to be different in each fraction. In fraction-2 the secondary component is copaene, while the minor components are iso-eugenol and alpha caryophyllene. In fraction-3 which is a secondary component is copaene, iso-eugenol and alpha caryophyllene. Meanwhile, the main component in fraction-4 is only eugenol, while the secondary components are beta caryophyllene, alpha caryophyllene, cadinene while the minor components are caryophyllene oxide and iso-eugenol. The fractionated components showed that the eugenol increased with the increasee of process temperature. The copaene component with high concentration is found in fraction-2, while beta caryophyllene and alpha caryophelene are found to be high in fraction-3.

The percentage of components detected in $100 \%$ on crude clove oil, while on fraction-2, fraction-3, fraction- 4 and residue is $99.8 \%, 95,9 \%, 87.7 \%$, and $94.9 \%$ sequentially. Eugenol is a phenylpropanoid compound with a phenol functional group [15]. In this study, eugenol contained in crude clove oil as much as $68.1 \%$ is also contained in all fractions with values $27.9 \%, 54.7 \%, 75.9 \%$ and $84.1 \%$ for fraction- 2 , fraction-3, fraction- 4 and residue, respectively. The highest concentration of eugenol was found in the residue which is the final product of the fractionation process. Generally, clove oil is produced by hydrodistillation, steam distillation or dry distillation of a plant. Eugenol produced by the hydrodistillation process is $79 \%$ and more than 30 other components [8].

Table 1. Temperature of fractionation process and gc-ms chromatography of crude clove oil and its fraction

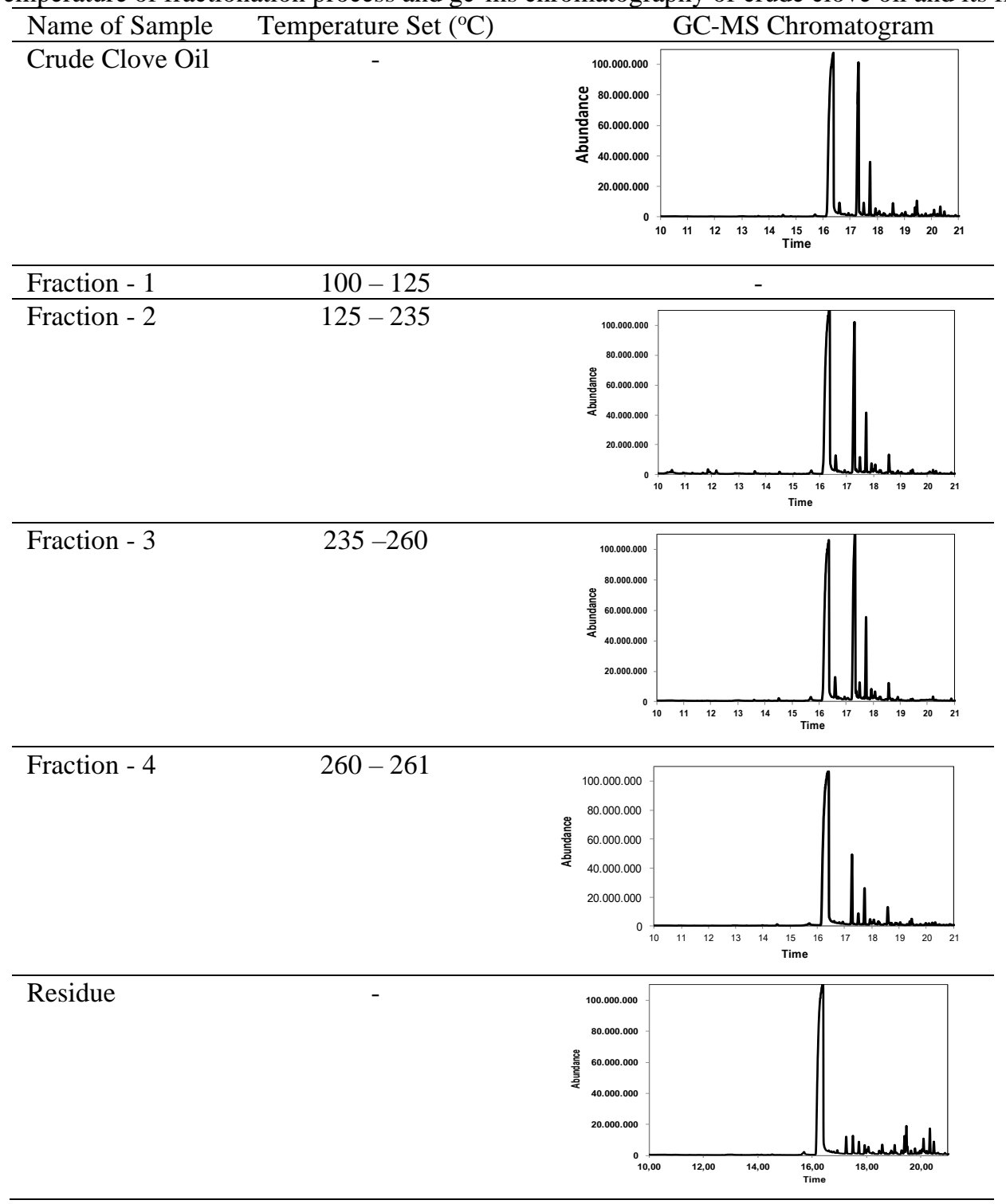


Table 2. Chemical Composition

\begin{tabular}{|c|c|c|c|c|c|c|}
\hline \multirow[b]{2}{*}{ RT } & \multirow[b]{2}{*}{ Composition } & \multicolumn{5}{|c|}{ Percentage $(\%)$} \\
\hline & & Crude Clove Oil & Fraction - 2 & Fraction - 3 & Fraction - 4 & Residue \\
\hline 16.4 & Eugenol & 68.1 & 27.9 & 54.7 & 75.9 & 84.1 \\
\hline 16.6 & Copaene & 1.3 & 6.1 & 2.0 & - & - \\
\hline 17.3 & Beta Caryophyllene & 21.1 & 23.8 & 30.5 & 5.8 & 1.4 \\
\hline 17.5 & Iso-Eugenol & 1.6 & 0.9 & 1.4 & 0.9 & 1.4 \\
\hline 17.7 & Alpha Caryophyllene & 4.0 & 0.7 & 5.9 & 2.8 & 0.9 \\
\hline 18.6 & Cadinene & 0.9 & - & 1.4 & 1.7 & 0.8 \\
\hline 19.5 & Caryophyllene Oxide & 1.9 & - & - & 0.6 & 2.9 \\
\hline 20.1 & Caryophylla & 0.4 & - & - & - & 1.3 \\
\hline 20.3 & Beta Caryophylla & 0.7 & - & - & - & 2.1 \\
\hline
\end{tabular}

Note : RT $=$ Retention time

This study, although the boiling point of eugenol is known to be around $254 \mathrm{oC}$, the results of the fractionation showed that not all eugenol can be separated and collected in one pot with a fractionation temperature of $235-260{ }^{\circ} \mathrm{C}$. This is because the temperature setting range in the fractionation column was too large. In the fractionation process to obtain components with the high level of purity, the fractionation process can be carried out gradually with a small temperature range. In this study, the desired fraction is a complex compound that is expected to not cause allergies. There are about 79 types of essential oils that cause skin allergies [3]. Copaene and caryophyllene are terpene compounds commonly contained in essential oils [7, 4, 16]. In this study, copaene is contained in crude clove oil, as well as in fraction-2 and fraction-3 with significantly different concentrations. It happens due to the process conditions for fraction-2 correspond to the boiling point of copaene around $124 \mathrm{oC}$. While beta and alpha caryophyllene was detected in all samples with significantly different concentrations for each fraction. The highest concentration of caryophyllene component which has a boiling point between $262-264{ }^{\circ} \mathrm{C}$ was in fraction-3 which operated at a fractionation temperature setting at $235-260{ }^{\circ} \mathrm{C}$.

\section{Antioxidant Activity}

Essential oils are natural antioxidants that are expected to replace synthetic antioxidants. Essential oils are a mixture of complex organic compounds with different functional groups. The composition of functional group determines the organoleptic properties and biological activities including antioxidants [17]. Eugenol with a phenol group is known to have high antioxidant activity [2]. Copaene, caryophyllene and cadinene are common terpene groups in essential oils. Functional groups of terpenes with alpha or gamma isomers have high antioxidant activity compared to other terpene isomers $[3,17]$.

In this study, the antioxidant concentration of clove oil is calculated from the calibration curve of ascorbic acid as a standard, the test solution is shown in Figure 1. Ascorbate is one of the most important vitamins in the plant material. The color of the solution is an indicator of the concentration of antioxidants. The color of a solution becomes increasingly faded with the a higher concentration of antioxidants. It can be seen that almost all sample solutions have higher concentration than the standard. High concentration indicates high activity.
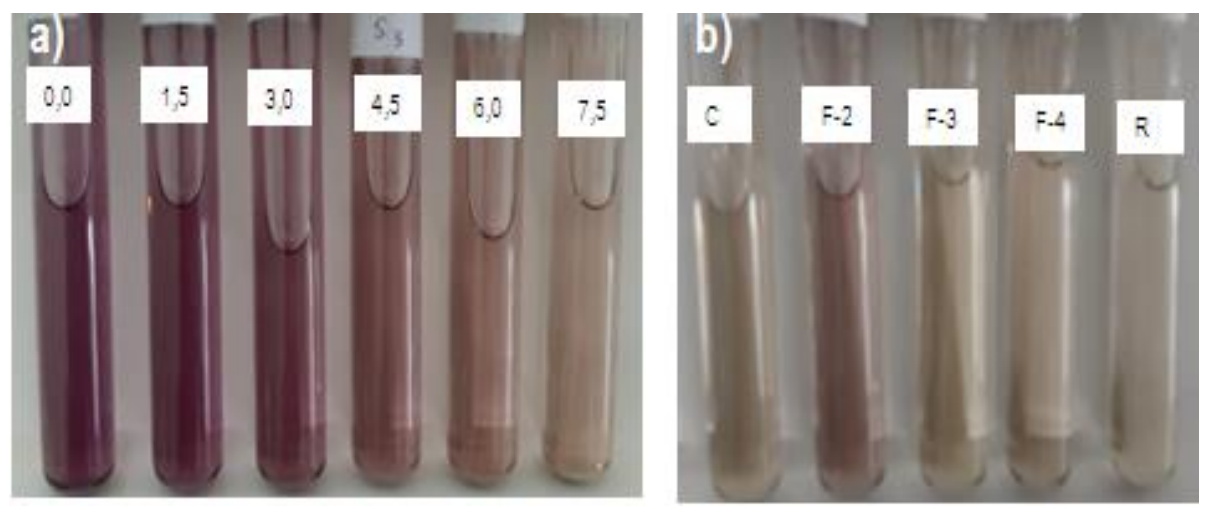

Figure 1. Antioxidant test solution a) ascorbic acid as standard $(0.0 \mathrm{mg} / \mathrm{L}, 1.5 \mathrm{mg} / \mathrm{L}, 3.0 \mathrm{mg} / \mathrm{L}, 4.5 \mathrm{mg} / \mathrm{L}, 6.0 \mathrm{mg} / \mathrm{L}$, $7.5 \mathrm{mg} / \mathrm{L}, \mathrm{b})$ clove oil solution (crude, fraction-2, fraction-3, fraction-4 and residue).

The antioxidant concentration of crude clove oil and then fractionation product namely fraction-2, fraction-3, fraction4 and residue were $10.1 \mathrm{mg} / \mathrm{L}, 7.9 \mathrm{mg} / \mathrm{L}, 10.2 \mathrm{mg} / \mathrm{L}, 9.8 \mathrm{mg} / \mathrm{L}$ and $10.2 \mathrm{mg} / \mathrm{L}$, respectively as shown in Figure 2 . It showed that the concentration of antioxidants in the sample was not significantly different, except for the sample fraction2 which was significantly lower than the other samples. Even though the concentration of eugenol components is low, the antioxidant activity in clove oil can be minimize lipid oxidation, retarding the formation of toxic oxidation products 
and prolonging the shelf life of pharmaceutical products [7]. Furthermore, the antioxidant properties of oils with high substituted phenol such as eugenol content are able to significantly inhibit the oxidation process [9][18].

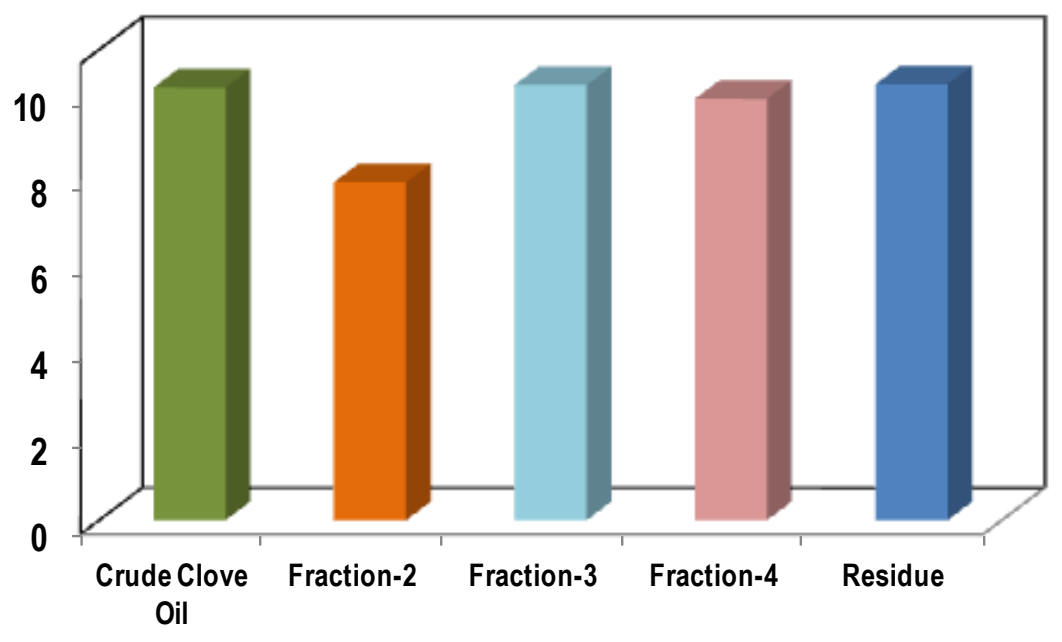

Figure 2. Antioxidant concentration of crude clove oil, fraction-2, fraction-3, fraction-4 and residue

\section{Skin Irritation Index}

Essential oils and their component are widely used topically on mucous membranes and skin, so testing for potential allergy on the skin is necessary. The potential for essential oil allergy on the skin can be known by knowing the skin irritation index. In general, the method used to obtain the skin irritation index is the patch test method [3]. Allergy potential testing is necessary to avoid the use of essential oil products that cause skin irritation (erytherma clinical evaluation). Table 3 showed the results of the evaluation of irritation level from 33 people as subjects with various ages. The irritation index (M.I.I.) with numbers of 0.00-0.20 indicated no irritation or can be ignored. M.I.I. from 0.20 to 0.50 indicated mild irritation, while M.I.I from 0.50 to 2.00 indicated moderate irritation, and M.I.I from 2.00 to 3.00 indicated severe irritation. Based on test results using crude clove oil sample showed that the use of $10 \%$ crude clove oil could irritate to the skin, this is indicated by M.I.I. of 0.39. On the other hand, the use of fraction-3 which has an M.I.I. 0.06 is non-irritating. The irritant properties of essential oils are determined by the composition of the components that compose them. The groups with high irritant potential are phenol, alcohol, aldehyde, ketone and ether respectively. Phenol, monoterpene alcohols and aromatic aldehydes have the highest irritant properties compared to monoterpene aldehydes, ketones and ethers. Eugenol and isoeugenol are phenylpropanoid phenolic compounds with lower irritant potential than monoterpene phenols such as thymol and carvacrol [3].

Table 2. Erythema Clinical Evaluation Results

\begin{tabular}{rrlrr}
\hline No & \multirow{2}{*}{$\begin{array}{c}\text { Age } \\
\text { (year) }\end{array}$} & Gender & \multicolumn{2}{c}{ Score } \\
\cline { 4 - 5 } 1 & 23 & Female & 0,5 & Fraction - 3 \\
2 & 43 & Female & 0 & 0 \\
3 & 31 & Male & 0 & 0 \\
4 & 38 & Female & 0,5 & 0 \\
5 & 30 & Female & 2 & 0,5 \\
6 & 44 & Female & 2 & 0 \\
7 & 36 & Female & 0 & 0 \\
8 & 40 & Female & 2 & 0 \\
9 & 48 & Female & 0 & 0 \\
10 & 28 & Female & 1 & 0 \\
11 & 49 & Female & 0 & 0 \\
12 & 39 & Male & 0 & 0 \\
13 & 39 & Male & Not Exploited & Not Exploited \\
14 & 41 & Female & 0 & 0 \\
15 & 49 & Female & Not Exploited & Not Exploited \\
16 & 39 & Male & 0 & 0 \\
17 & 53 & Female & 0,5 & 0 \\
18 & 44 & Female & 0,5 & 0 \\
19 & 41 & Female & 0,5 & 0 \\
20 & 49 & Female & & 0 \\
21 & 45 & Female & 0
\end{tabular}




\begin{tabular}{rrlrr}
22 & 45 & Female & 0 & 0 \\
23 & 23 & Male & 0,5 & 0 \\
24 & 24 & Female & 0 & 0 \\
25 & 47 & Male & 0 & 0 \\
26 & 48 & Female & 0 & 0 \\
27 & 24 & Female & 0 & 0 \\
28 & 35 & Female & 1 & 0 \\
29 & 19 & Female & 0 & 0 \\
30 & 18 & Female & 1 & 1 \\
31 & 32 & Female & 0 & 0 \\
32 & 58 & Female & 0 & 0 \\
33 & 35 & Female & 0 & 0 \\
\hline \multicolumn{5}{c}{ Mean Irritation Index (M.I.I.) } \\
\hline \multicolumn{5}{c}{ Maximum } \\
\hline
\end{tabular}

Note $: 0=$ no evidence of any effect, $0,5=$ very mild erythema, $1=$ mild, $2=$ moderate, $3=$ marked

In this study, the components of caryophylla and beta caryophylla (see Tabel 2) which are monoterpene aldehyde compounds play a role in increasing the potential for skin irritation when mixed with eugenol components. These components increase the potential for skin irritation in raw clove oil.

\section{CONCLUSION}

Commercial tempeh inoculums and cassava waste pulp as LA producers makes the effective fermentation process for bioplastic technology. The optimum condition at a cassava waste pulp concentration of $20 \mathrm{~g} / \mathrm{L}$ and $0.30 \%$ (w/v) tempeh inoculum with 72 hours of incubation time yields a maximum LA production of $6.65 \mathrm{~g} / \mathrm{L}$. However, a well-established study on microorganisms producing LA with renewable raw material using the RSM technique still requires more research to be generalized and applied to a broader LA industry scope.

\section{ACKNOWLEDGEMENT}

This research was funded by Research and Technology/Brin through LPDP with contract number 167/E1/PRN/2020. Thanks to BioTrop IPB and PT SIL for supplying raw materials. Thanks to Mr. Sudirman who has helped proofreading this manuscript.

\section{REFERENCES}

[1] R. A. Larayetan, O. O. Okoh, A. Sadimenko, and A. I. Okoh, "Terpene constituents of the aerial parts, phenolic content, antibacterial potential, free radical scavenging and antioxidant activity of Callistemon citrinus (Curtis) Skeels (Myrtaceae) from Eastern Cape Province of South Africa," BMC Complement. Altern. Med., vol. 17, no. 1, pp. 1-9, 2017.

[2] R. Pérez-Rosés, E. Risco, R. Vila, P. Peñalver, and S. Cañigueral, "Biological and Nonbiological Antioxidant Activity of Some Essential Oils," J. Agric. Food Chem., vol. 64, no. 23, pp. 4716-4724, 2016.

[3] A. Sarkic and I. Stappen, "Essential oils and their single compounds in cosmetics-a critical review," Cosmetics, vol. 5, no. 1, pp. 1-21, 2018.

[4] M. Valdivieso-Ugarte, C. Gomez-Llorente, J. Plaza-Díaz, and Á. Gil, "Antimicrobial, antioxidant, and immunomodulatory properties of essential oils: A systematic review," Nutrients, vol. 11, no. 11, pp. 1-29, 2019.

[5] M. Rafi et al., "Total phenolics, flavonoids, and anthocyanin contents of six Vireya Rhododendron from Indonesia and evaluation of their antioxidant activities," J. Appl. Pharm. Sci., vol. 8, no. 9, pp. 49-54, 2018.

[6] C. Jianu, C. Mișcă, D. Stoin, G. Bujancă, and L. G. A. Teodora, "Chemical composition and antioxidant properties of dill essential oil," Int. Multidiscip. Sci. GeoConference Surv. Geol. Min. Ecol. Manag. SGEM, vol. 18, no. 6.4, pp. 87-94, 2018.

[7] J. G. Xu, T. Liu, Q. P. Hu, and X. M. Cao, "Chemical composition, antibacterial properties and mechanism of action of essential oil from clove buds against staphylococcus aureus," Molecules, vol. 21, no. 9, pp. 1-13, 2016.

[8] I. Safrudin, A. Maimulyanti, and A. R. Prihadi, "Effect of crushing of clove bud ( Syzygium aromaticum ) and distillation rate on main constituents of the essential oil," Am. J. Essent. Oils Nat. Prod., vol. 2, no. 3, pp. 12-15, 2015.

[9] R. Ghadermazi, J. Keramat, and S. A. H. Goli, "Antioxidant activity of clove (Eugenia caryophyllata Thunb), oregano (Oringanum vulgare L) and sage (Salvia officinalis L) essential oils in various model systems," Int. Food Res. J., vol. 24, no. 4, pp. 1628-1635, 2017.

[10] H. Boulebd, "Comparative study of the radical scavenging behavior of ascorbic acid, BHT, BHA and Trolox: Experimental and theoretical study," J. Mol. Struct., vol. 1201, p. 127210, 2020.

[11] Y. Tu and T. Quan, "Oxidative stress and human skin connective tissue aging," Cosmetics, vol. 3, no. 3, pp. 1-12, 
2016.

[12] R. Muthukumarasamy, A. Ilyana, N. 'Afini Fithriyaani, N. A. Najihah, N. Asyiqin, and M. Sekar, "Formulation and evaluation of natural antioxidant cream comprising methanolic peel extract of Dimocarpus longan," Int. J. Pharm. Clin. Res., vol. 8, no. 9, pp. 1305-1309, 2016.

[13] G. G. Mohandas and M. Kumaraswamy, "Antioxidant activities of terpenoids from thuidium tamariscellum (c. Muell.) bosch. And sande-lac. A moss," Pharmacogn. J., vol. 10, no. 4, pp. 645-649, 2018.

[14] A. C. de Groot and E. Schmidt, "Tea tree oil: contact allergy and chemical composition," Contact Dermatitis, vol. 75, no. 3, pp. 129-143, 2016.

[15] J. Wan, S. Zhong, P. Schwarz, B. Chen, and J. Rao, "Influence of oil phase composition on the antifungal and mycotoxin inhibitory activity of clove oil nanoemulsions," Food Funct., vol. 9, no. 5, pp. 2872-2882, 2018.

[16] P. E. Kendra, W. S. Montgomery, M. A. Deyrup, and D. Wakarchuk, "Improved lure for redbay ambrosia beetle developed by enrichment of $\alpha$-copaene content," J. Pest Sci. (2004)., vol. 89, no. 2, pp. 427-438, 2016.

[17] B. Tohidi, M. Rahimmalek, and A. Arzani, "Essential oil composition, total phenolic, flavonoid contents, and antioxidant activity of Thymus species collected from different regions of Iran," Food Chem., vol. 220, pp. 153$161,2017$.

[18] D. P. Bezerra, G. C. G. Militão, M. C. De Morais, and D. P. De Sousa, "The dual antioxidant/prooxidant effect of eugenol and its action in cancer development and treatment," Nutrients, vol. 9, no. 12, pp. 1-15, 2017. 